\title{
Doenças terminais, conhecimento essencial para o profissional da saúde
}

\author{
Terminal diseases, essential knowledge for the health professional
}

\author{
Carolini Graciela da Silva ${ }^{[0]}$, Lucas Indalêncio Cota ${ }^{[a]}$, Rodrigo Ortega Vieira ${ }^{[0]}$, \\ Vanessa Debacher de Arrazãa ${ }^{[a]}$, Luiz Arthur Rangel Cyrino ${ }^{[b]}$,
}

\footnotetext{
[a] Acadêmicos do curso de Psicologia da Universidade da Região de Joinville (Univille), Joinville, SC Brasil, e-mails:

carolgraciela@gmail.com, lucascgodo@hotmail.com, ortega26_1@hotmail.com, vdebacher@gmail.com

${ }^{[b]}$ Médico, mestre em Neurociência pela Universidade Federal de Santa Catarina (UFSC), especialista em Terapia Nutricional Total, especialista em Medicina do Trabalho, especialista em Homeopatia, professor do Curso de Psicologia e do curso de Farmácia da Universidade da Região de Joinville (Univille), Joinville, SC - Brasil e-mail: rangel7@uol.com.br
}

Recebido: 09/08/2011 Received: 08/09/2011

Aprovado: $13 / 10 / 2011$ Approved: 10/13/2011

\section{Resumo}

Saber lidar com paciente em fase terminal é, ainda, extremamente difícil, mesmo com os avanços na tecnologia e da medicina, na medida em que a morte é enfrentada como um tabu pela sociedade, as probabilidades de reversão da doença são mínimas e os profissionais da saúde carecem de treinamento para lidar com essa questão. Esse último fator é preocupante, porque os indivíduos que se encontram nessa fase vivenciam diversos conflitos, entre eles sentimentos de impotência, angústia e temor em relação à vida e necessitam de um suporte ativo por parte da família e da equipe médica. 0 presente artigo visa desse este assunto, enfatizando a atuação desses profissionais que devem estar atentos para as questões presentes na vivência cotidiana de seus pacientes. Inicialmente serão expostos alguns conceitos de "paciente terminal" e a problematização do tema, que sustentam uma discussão importante para entender o assunto com clareza e cientificidade. Serão apresentados também alguns métodos bastante discutidos e questionados na área de saúde como a eutanásia e a distanásia, sem deixar de abordar durante todo o trabalho a parte do paciente terminal, "sujeito" central de todo o processo. Por fim, esta pesquisa tem como intuito enriquecer conhecimentos para futuros profissionais da saúde, já que essa preparação se faz necessária para oferecer auxílio aos envolvidos nessa questão.

Palavras-chave: Estado terminal. Tratamento paliativo. Eutanásia. Distanásia.

\begin{abstract}
Dealing with terminally ill is, still, extremely difficult, even with advances in technology and medicine, because death is dealt with as a taboo by society, odds of reversal disease are minimal and health professionals lack the training for this issue. This latter is a worrying factor, because individuals who are experiencing this stage have various conflicts, including feelings of helplessness, anguish and fear about life and require an active support from family and medical team. This article aims to address on this subject, emphasizing the role of these professionals should be aware of the issues present in the daily life of their patients. Initially will be exposed to some concepts of "terminally ill" and questioning the subject, who hold an important discussion to understand the subject with clearly and scientifically, then some rather discussed and questioned in the midst of health such as euthanasia and futility, while to address all the work during the part of the
\end{abstract}


terminal patient "subject" core of the whole process. Finally this research has the intention to enrich knowledge for future health professionals, since this preparation is necessary to provide assistance in the midst of this issue.

Keywords: Critical illness. Palliative care. Euthanasia. Dysthanasia.

\section{Introduç̃̃o}

A morte, apesar de ser parte natural de todas as formas de vida, tem interpretação ainda carregada de valores e uma dimensão simbólica, que se relaciona à psicologia e também às ciências sociais. Isso é evidenciado por Kovács (2008, p. 12) ao afirmar que "a psicologia como ciência, arte, reflexão e prática cuida da questão do homem, das suas relações com o outro e com o mundo, com a vida e também com a morte". Commbinato e Queiroz (2006, p. 210) falam sobre a concepção de morte em nossa cultura ao dizer que "para o homem ocidental moderno, a morte passou a ser sinônimo de fracasso, impotência e vergonha. Tenta-se vencê-la a qualquer custo e, quando tal êxito não é atingido, ela é escondida e negada". Dessa forma, com essa visão e com os avanços da medicina, a morte é vista como algo que deve ser evitado, como um fracasso aos profissionais de saúde, mesmo lidando com este fator constantemente em sua prática diária. No entanto, "a aceitação da morte constitui certamente um dos maiores sinais de maturidade humana. Daí a necessidade de uma educação sobre a morte, ... porque a morte, paradoxalmente, pode ensinar a viver" (Neto \& Oliveira, 2004 p. 355).

As concepções ligadas ao ato de morrer são um grande tabu de discussão social. Não é possível uma discussão clara a respeito da morte em si, uma vez que as pessoas que passaram pela experiência de morrer não nos podem relatá-la, e como resultado disso, as formas de tratamento em relação ao paciente em condições terminais ainda não alcançou o consenso, como Moritz et al. (2009, p. 307) explanam ao dizer que:

Apesar do debate, de âmbito mundial, visando à definição do melhor atendimento ao paciente com doença terminal, esse questionamento ainda permanece sem resposta definitiva. Porém não há dúvidas que as práticas de final de vida devem priorizar o melhor interesse do paciente, respeitando seus sen- timentos e desejos de seus familiares e a adequada comunicação entre todos os envolvidos no processo.

É possível analisar e estudar os fenômenos envolvidos em torno da morte, a partir de indivíduos diagnosticados com doenças que lhe alertam de um final iminente. Porém, como é ressaltado por Borges et al. (2006, p. 362):

As pesquisas que tem como objetivo analisar as intervenções psicológicas em situações que envolvem mortes são ainda muito precárias, recentes e escassas, mas algumas destas pesquisas trazem como sugestões algumas estratégias de suporte psicológico que se baseiam nos princípios de cuidados paliativos envolvendo a qualidade de vida e o controle da dor do paciente.

Os pacientes terminais enfrentam muita dor e sofrimento em razão do abandono das atividades diárias, do abandono pelos familiares e da incapacidade de se relacionar com outras pessoas devido a efeitos colaterais de medicamentos e tratamentos que podem ofender sua dignidade (Alves, 2011). Isso torna o doente dependente dos conhecimentos e da preparação dos profissionais da saúde.

Este artigo tem como objetivo abordar a questão da prática desses profissionais diante das doenças terminais, bem como entender como essa situação é complicada para o indivíduo e para todos que o rodeiam.

\section{0 paciente terminal}

A morte faz parte do desenvolvimento humano... e acompanha o ser humano no seu ciclo vital, deixando suas marcas. Como preparar pessoas para esse fato tão presente na existência? Esse desafio é ainda mais urgente para os profissionais de saúde e educação (Kovács, 2005, p. 485). 
As doenças terminais, que ao lidar com a ideia de morte, ainda são, pelo alto nível de envolvimento pessoal e pela complexidade para todas as partes envolvidas, motivos de resistência ao ser abordado em meio a nossa cultura. Como ressalta Batista e Schramm (2004, p. 32): “Sem embargo, a morte está longe de ser um tema de fácil abordagem e manejo, sobretudo nos dias atuais - mas não somente hoje".

Entretanto, o número de pesquisas e estudos sobre o conceito de "doença terminal" está aumentando e começando a ser melhor descutido entre os profissionais da saúde. Segundo Gutierrez (2001, p. 92), “... a conceituação de paciente terminal não é algo simples de ser estabelecido, embora frequentemente nos deparemos com avaliações consensuais de diferentes profissionais".

É sabido que trabalhar com o paciente em fase de terminalidade é complicado pelos vários fatores emocionais, estressantes e frustrantes que estão envolvidos; para que esse trabalho seja aplicado com maior facilidade e competência, é necessário que cada profissional tenha um conceito claro de doença terminal formado que embase sua atuação. Ainda segundo Gutierrez (2001, p. 92), a terminalidade se dá quando:

... se esgotam as possibilidades de resgate das condições de saúde do paciente e a possibilidade de morte próxima parece inevitável e previsível. 0 paciente se torna "irrecuperável" e caminha para a morte, sem que se consiga reverter este caminhar.

Contudo, para Kovács (2008, p. 195), o conceito de terminalidade é relativo.

A questão da temporalidade é relativa, pois, ao dizermos que um idoso ou um paciente com doença grave está mais próximo da morte, este fato é constantemente contrariado, visto que, muitas vezes, pessoas saudáveis ou mais jovens morrem mais cedo do que aqueles que já estão "marcados para morrer".

Ao longo do processo, a doença avança e a terminalidade é imposta como uma situação real; nesse momento ocorrem inúmeros problemas de ordem clínica, ética, social e psicológica. Os conflitos de ordem psicológica, abordados adiante, colocam os pacientes diante de impasses e demandas muitas vezes incomensuráveis.
A não possibilidade de cura de um paciente rompe com os limites terapêuticos, mas de forma alguma com as possibilidades de cuidar e proporcionar dignidade e respeito aos limites de quem não quer viver sofrendo. Portanto, para os profissionais da saúde, é imprescindível que o cuidado se torne mais humano e digno, algo que vai muito além de uma assistência puramente técnica (Campos, Barbosa \& Santana, 2009, p. 84).

0 paciente que enfrenta o período da terminalidade precisa ter suas necessidades especiais identificadas, para que seja preservada sua qualidade de vida nessa fase, ou seja, o doente terminal é um sujeito que antes de tudo é uma pessoa com a sua vida própria, única e singular.

Muitas vezes, o rótulo terminal traz a falsa ideia de que não há mais nada que se possa fazer pelo paciente, esta é uma crença errônea, pois é justamente neste momento que a pessoa necessita mais de ajuda tanto física quanto psíquica. Os desejos e metas continuam enquanto há vida, e o paciente ainda não morreu (Kovács, 2008, p. 206).

Em meio a todo esse processo, é importante que os interesses e sentimentos do paciente e de seus familiares sejam levados em consideração, bem como a busca contínua para amenizar seus sofrimentos emocionais e físicos. Deve-se considerar que o sofrimento, a negação da terminalidade, os sentimentos de impotência atingem todos envolvidos na situação, ou seja, paciente, família e equipe de saúde responsável. Gutierrez (2001, p. 92) ressalta que:

De qualquer forma, paciente, família e equipe situam-se neste ponto da evolução da doença frente a impossibilidades e limites, de maneira que reconhecer o fim parece ser a dificuldade maior. Denegar este conhecimento determina estragos nos que partem e nos que ficam. Morrer só, entre aparelhos, ou rodeado por pessoas às quais não se pode falar de sua angústia, determina um sofrimento difícil de ser avaliado, mas sem dúvida, suficientemente importante para ser levado em conta. Os que ficam, por outro lado, têm que se haver com a culpabilidade, a solidão e a incômoda sensação de não ter feito tudo o que poderia. 
Angerami-Camom (2003) explica que a dor é a causa mais obvia do sofrimento e pode surgir de um ferimento ou de uma doença progressiva, funcionando como um alarme para que o corpo retorne ao seu funcionamento normal. A dor física é a que recebe maior atenção quando se trata de cuidados paliativos, conforme ressalta Sousa (1997, p. 58): “... por ser difícil de manejá-la e ter grande repercussão no paciente e também nas pessoas que o cercam, seja familiar, amigo ou equipe".

Portanto, a saúde hospitalar precisa lidar com muitas dessas questões, levando-se em consideração que essa fase é complexa ao paciente, e a humanização de uma equipe multidisciplinar é de extrema importância, uma vez que as pessoas em condições terminais são muito dependentes dos cuidados de terceiros. Menezes (2004) assinala que é justamente essa dependência que justifica o trabalho da equipe multidisciplinar, evidenciado a necessidade de profissionais de diversas áreas, sendo que a visão de qualidade de vida irá variar conforme a área do profissional, mas estando "ancorados em um máximo de controle dos sintomas".

\section{0 papel do profissional da saúde diante da doença terminal}

Será que o médico, ainda visto como o principal profissional ligado ao tema, está preparado para lidar com as questões envolvidas nesse processo tão complexo, e ainda mais, com a ideia de morte? As pesquisas que instigam essa questão e foram encontradas no presente estudo são bastante relevantes. Segundo Batista e Schramm (2004, p. 33), "desde cedo, o estudante de medicina é moldado para ver a morte como 'o maior dos adversários', o qual deverá ser sempre combatido e, se possível, vencido...". Isto é ressaltado ainda por Vianna e Piccelli (1998, p. 21) ao comentarem que:

Nas duas últimas décadas, a literatura científica tem sido pródiga em publicações sobre as atitudes do médico diante da morte e do paciente terminal. Entretanto, há poucos indícios capazes de definir se tais reações surgem durante o exercício da profissão, em face de situações concretas envolvendo a morte de pacientes, ou se há predisposições trazidas ou desenvolvidas durante a formação médica.
Essa ideia pode fazer com que o médico se torne reticente para lidar com pacientes enfermos e em fase de terminalidade, já que esta é considerada por ele sinal de falta de competência ou de fracasso. Pazin-Filho (2005, p. 20) confirma essa situação ao dizer que:

... a morte passa a ser entendida como falha da medicina e não como parte integrante da vida. A visão da morte como um erro da medicina, um insucesso de um tratamento, gera ansiedade e cobrança por parte da população e dos próprios médicos.

Essa discussão suscita uma questão interessante a ser discutida, já que, como pudemos ver, no processo da doença terminal não só a família e o paciente experimentam uma desestabilidade emocional, mas também toda a equipe médica que se torna intensamente envolvida. Dessa forma, faz-se necessária a existência de uma equipe que auxilie o médico e o paciente a lidar com esses problemas no meio hospitalar.

O hospital é uma instituição complexa, que envolve um grande número de especialidades. Esses profissionais são preparados para tomar decisões importantes em curto espaço de tempo. Tradicionalmente, tais decisões competem aos médicos. No entanto, com o aparecimento de novas especialidades, os médicos contam hoje com o auxílio de diversos profissionais de campos emergentes (Tonetto \& Gomes, 2007, p. 90).

É nesse meio que as equipes multidisciplinares, ou seja, aquelas em que existem vários profissionais atendendo o mesmo paciente de maneira independente tornam-se importantes, até mesmo para que haja colaboração entre as equipes, existindo uma troca de informações. Segundo Shimizu e Guitierrez (1997, p. 257): "a troca de informações e conhecimentos nas reuniões multidisciplinares favorece $o$ crescimento e desenvolvimento dos profissionais tornando-os mais competentes, conscientes, preparados e fortalecidos....".

É importante salientar que o indivíduo deve ser acolhido, suas necessidades e vontades devem ser aceitas, principalmente enfatizando o direito do indivíduo de morrer com dignidade; isso inclui morrer sem dor, morrer em casa com seus entes queridos, sem sofrimento inútil e principalmente morrer 
sem "falsas expectativas". Para confirmar essas palavras, Sousa (1997, p. 114) mostra alguns direitos do paciente em fase terminal, expostos no esboço de proposta para possíveis normas internacionais de procedimento (Nações Unidas) para a proteção de pessoas que sofrem de doenças terminais; aqui citamos dois deles:

Todos os pacientes são dignos para decidir quando parar o tratamento. Em caso onde o paciente não é mais capaz de tais decisões, instruções antecipadas deixadas pelo paciente deverão ser seguidas... Um paciente pode solicitar a presença de uma pessoa ou pessoas da escolha do paciente durante o procedimento de obtenção do consentimento (Sousa, 1997, p. 114).

\section{Eutanásia e distanásia}

E quando a doença torna-se tão invasiva a ponto de causar sofrimento irredutível e morte inexorável ao paciente? Será que práticas que interferem ou antecedem o processo de morrer são aceitáveis nesses casos? Essas indagações vêm sendo feitas principalmente depois do aparecimento da chamada Bioética, um campo disciplinar comprometido com os conflitos morais na área da saúde. Conforme pontua Schramm (2008, p. 20):

Esta disciplina, que se propõe a investigar a moralidade dos atos humanos que podem alterar, de forma significativa e irreversível, os sistemas autopoiéticos, também irreversíveis, representados pelos seres vivos, vem se debruçando sobre toda sorte de conflitos e dilemas que emergem no binômio vida/morte, mais precisamente em relação à finitude e ao significado da expressão morrer bem...

A primeira prática aqui discutida é a eutanásia. De acordo com Cruz (2005, p. 18), "a palavra eutanásia tem origem grega e significa boa morte, podendo ser compreendida como morte serena e sem sofrimento..."; para Torreão (2003, p. 123), é um processo que "tem como objetivo abreviar a vida, findando um sofrimento intolerável através de ações diretas que levarão à morte".

Há profissionais que entendem a prática da eutanásia como resultado de um direito individual de deliberar a própria existência, existindo modos de praticá-la como descritos abaixo:

Há a eutanásia ativa (aquela em que se induz a morte pela administração de medicamentos, por exemplo) e a eutanásia passiva (aquela em que se retiram mecanismos de sustentação artificial da vida ou se retiram medicamentos), podendo cada uma delas ser classificada como voluntária ou involuntária. A eutanásia é voluntária quando fruto da deliberação individual, informada e esclarecida de cada pessoa, e involuntária quando a pessoa não se pronunciou e não há como conhecer sua opinião, ou mesmo quando ela não desejava a prática da eutanásia (Diniz, 2006, p. 1743).

Atualmente ainda não existe uma lei que regulamente a eutanásia, por ser um assunto que envolve muitos fatores. De acordo com o Artigo 5o da Constituição Federal (Brasil, 1988):

todos são iguais perante a lei, sem distinção de qualquer natureza, garantindo-se aos brasileiros e aos estrangeiros residentes no País a inviolabilidade do direito à vida, à liberdade, à igualdade, à segurança e à propriedade...

E coloca em seu terceiro termo que "ninguém será submetido a tortura nem a tratamento desumano ou degradante" (Brasil, 1988) . Portanto, "a morte termina a existência de uma pessoa, e, com isto cessam seus direitos; mas o paciente terminal, mesmo que em agonia, mantém a personalidade jurídica, pois ainda vive" (Kovács, 2003, p. 114).

No caso do enfermeiro, um dos profissionais da equipe multidisciplinar, de acordo com Biondo, Secco e Silva (2009, p. 4), ele “... deve ser ciente do seu código de ética, o qual traz claramente em seu Artigo n. 29, quanto às proibições: Promover a eutanásia ou participar em prática destinada a antecipar a morte do cliente".

Ainda, segundo Diniz (2006, p. 1743), “... a segunda forma de entender a eutanásia é considerá-la como sinônimo de homicídio ou de suicídio, e ainda um terceiro ... o suicídio assistido, que também se aproxima do debate sobre eutanásia...."

Já a distanásia, conforme Biondo, Secco e Silva (2009, p. 2) “...é sinônimo de tratamento fútil ou inútil, sem benefícios para a pessoa em sua fase terminal. É o processo pelo qual se prolonga meramente 
o processo de morrer, e não a vida propriamente dita...", ou seja, são procedimentos que tentam prolongar a vida do paciente artificialmente, utilizando-se de recursos máximos da medicina, durante o tempo necessário. Segundo Kovács (2003, p. 145), “... o médico será obrigado a prolongar a vida se este for o desejo explícito do paciente ou de seus familiares. Portanto, a distanásia não é imputável, mesmo se comprovado que causa muito sofrimento...". Conforme Kipper (1999) citado por Kovásc (2003):

... com todos os problemas econômicos do Brasil, ainda se mantêm os pacientes em estado terminal por muito tempo nas UTIs, porque os profissionais de saúde temem as conseqüências do desligamento dos aparelhos, e se sentem sozinhos nestes momentos. A família precisa ser informada, e ter tempo para elaborar o que significa este desligamento de aparelhos.

Como pudemos ver, esse ainda é um assunto bastante delicado, que envolve o direito de morrer do paciente em contraposição a muitos outros fatores que geram dúvidas em saber se a eutanásia e a distanásia são procedimentos que devem ou não ser aceitos. De acordo com Sadala e Silva (2008), a complexidade desse tema é explorada por SiqueiraBatista \& Schram (2004), quando:

... ampliam o debate sobre a bioética do fim da vida, geralmente tratada como uma questão relativa ao indivíduo, para uma perspectiva social desta problemática, passando a ser vista como um problema de Saúde Coletiva - dado que o prolongamento da vida das pessoas e o prolongamento do processo de morrer implicam a discussão do uso adequado dos investimentos públicos, garantindo para todos, ao final da vida, o acesso à morte digna e assistida.

O que realmente importa é que o paciente nesta fase precisa ser respeitado independente das políticas e dos resultados desses tantos debates.

\section{Considerações finais}

A elaboração de questões ligadas ao fim da vida encontra grande resistência na cultura ocidental; como Commbinato e Queiroz (2006) afirmam, o fim de um ciclo é visto como uma perda irreparável de objetos aos quais se depositam energias emotivas causando o apego. A questão do apego é uma parte importante para se entender a forma como tal sociedade lida com a morte, pois uma vez que tudo deve ser aproveitado ao máximo, devido às relações efêmeras e passageiras, criam-se vínculos que não compreendem a perda.

Por tais motivos, segundo Menezes (2004), pesquisas relacionadas à morte, uma etapa que causa angústia na maioria das pessoas, são precárias e escassas, principalmente a respeito da representação que a pessoa doente e seus familiares apresentam em relação à morte. Fica evidente a importância de indagar quais seriam as representações que o paciente e seus familiares de diferentes contextos sociais constroem acerca de "boa morte", ou seja, a forma mais adequada de se encarar esse momento tão difícil. Encontram-se muitos artigos sbre formas de prevenir, deter ou reverter o processo da morte, porém poucos estudos realizados sobre a vivência da morte como algo natural, buscando formas de proceder da melhor maneira possível em casos iminentes.

Com este artigo, pôde-se compreender os papéis dos sujeitos que lidam diretamente com a real presença da morte, como ela sendo o resultado final de seu trabalho. Para alguns profissionais da saúde, principalmente aqueles treinados para evitá-la e revertê-la, isso pode ser demasiadamente frustrante e desanimador. "A diferença entre as pessoas em geral e os profissionais de saúde: médicos, enfermeiros, psicólogos é que, na vida destes, a morte faz parte do cotidiano, tornando-se companheira de trabalho" (Kovács, 2005, p. 494).

Entretanto, como afirmam Gutierrez e Ciampone (2007), os indivíduos que têm a morte como algo que faz parte do cotidiano reconhecem o quanto o diagnóstico de uma doença grave, sem possibilidade de cura, irá caracterizar uma situação muito problemática que acarretará mudanças psicossociais e espirituais no indivíduo que o permitam enfrentar essa situação. Fica claro também que essas mudanças inesperadas vão desencadear também, mobilizações em familiares, amigos, em todos os relacionamentos significativos do paciente. Portanto, o profissional da saúde deve criar possibilidades para que o paciente possa compreender sua enfermidade e não focar somente a saúde, podendo, assim, facilitar a conscientização ou a aproximação da morte.

No extremo do processo, tem-se a pessoa que está morrendo, um morrer mais acelerado do que o 
natural. Esse indivíduo, que muitas vezes passa por uma série de procedimentos invasivos, sem poder necessariamente se posicionar diante de algumas decisões e vivencia emoções pelos que estão ao seu redor, têm a sua rotina marcada por diversos profissionais que parecem ainda não estar inteiramente preparados para lidar com suas reais necessidades. Assim, como corroborado pela Academia Nacional de Cuidados Paliativos (ANCP) (2009, p. 4) ao comentar sobre os cuidados paliativos:

Os pacientes fora de possibilidade de cura acumulam-se nos hospitais, recebendo invariavelmente assistência inadequada, quase sempre focada na tentativa de recuperação, utilizando métodos invasivos e alta tecnologia. Essas abordagens, ora insuficientes, ora exageradas e desnecessárias, quase sempre ignoram o sofrimento e são incapazes, por falta de conhecimento adequado, de tratar os sintomas mais prevalentes, sendo a dor o principal e mais dramático.

Ainda são necessários estudos mais aprofundados a respeito das relações que se dão no contexto da morte, porém está claro a partir dos tipos de pesquisas feitas que a visão que se têm do morrer pode e deveria ser modificada para um ambiente mais saudável ao lidar com pacientes em estágio terminal.

\section{Referências}

Academia Nacional de Cuidados Paliativos, [ANCP], (2009). Manual de Cuidados Paliativos. Rio de Janeiro: Diagraphic.

Alves, L. B. F. (2011). Paciente terminal: Reflexões sobre dilemas éticos e cuidados paliativos. Recuperado em 2 jul. 2011, de http://santosediniz.com.br/mba-em-gestao-de-planos-de-Saude/tcc/TCC-VICTOR-alves. pdf.

Angerami-Camom, V. A. (Org.). (2003). Atualidades em Psicologia da Saúde. São Paulo: Pioneira Thomsom Learning.

Batista, R. S., \& Schramm, F. R. (2004). Eutanásia: Pelas veredas da morte e da autonomia. Ciência \& Saúde Coletiva, 9(1), 31-41. doi:10.1590/ S1413-81232004000100004.
Biondo, C. H. Secco, L. M. D., \& Silva, M. J. P. (2009). Distanásia, eutanásia e ortotanásia: Percepções dos enfermeiros de unidades de terapia intensiva e implicações na assistência. Revista Latino-am Enfermagem, 17(5). doi:10.1590/S1413-73722006000200015.

Borges, A. D. V. S., Silva, E. F., Toniollo, P. B., Mazer, S. M., Valle, E. R. M., \& Santos, M. A. (2006). Percepção da morte pelo paciente oncológico ao longo do desenvolvimento. Revista Psicologia em Estudo, 11(2), 361-369.

Brasil. (1988). Constituição da República Federativa do Brasil. Brasília, DF: Senado Federal.

Campos, A. C. V., Barbosa, B. D. G, Santana, J. C. B., Baldessari, C. E. F., Paula, K. F., Rezende, M. A. E. et al. (2009). Cuidados paliativos aos pacientes terminais: Percepção da equipe de enfermagem. Bioethikós Centro Universitário São Camilo, 3(1), 77-86.

Commbinato, D. S., \& Queiroz, M. S. (2006). Morte: Uma visão psicossocial. Revista Estudos de Psicologia, 11(2), 209-216. doi:10.1590/S1413-294X2006000200010.

Cruz, T. F. S. (2005). Psicologia hospitalar e eutanásia. Revista da SBPH, 8(2).

Diniz, D. (2006). Quando a morte é um ato de cuidado: Obstinação terapêutica em crianças. Caderno de Saúde Pública, 22(8), 1741-1748. doi:10.1590/ S0102-311X2006000800023.

Gutierrez, P. L. (2001). 0 que é o paciente terminal? À beira do leito. Revista da Associação Médica Brasileira, 47(2), 92-92. doi:10.1590/S0104-42302001000200010.

Gutierrez, B. A. O., \& Ciampone, M. H. T. (2007). 0 processo de morrer e a morte no enfoque dos profissionais de enfermagem de UTIs. Revista Escola Enfermagem USP, 41(4), 660-667. doi:10.1590/ S0080-62342007000400017.

Kovásc, M. J. (2003). Bioética nas questões da vida e da morte. Revista Psicologia USP, 14. Recuperado em 8 maio 2011, de http://www.scielo.br/pdf/pusp/ v14n2/a08v14n2.pdf.

Kovács, M. J. (2005). Educação para a morte. Psicologia: Ciência e profissão, 25(3). Recuperado em 22 jun. 2011, de http://pepsic.bvsalud.org/scielo. php?pid=S1414-98932005000300012\&script $=$ sci arttext. 
Kovács, M. J. (2008). Morte e desenvolvimento humano. 3a ed. São Paulo: Casa do Psicólogo.

Neto, F. \& Oliveira, J. B. (2004). Validação de um instrumento sobre diversas perspectivas da morte. Análise Psicológica, 2(22), 355-367.

Menezes, R. A. (2004). Em Busca da boa morte: Antropologia dos cuidados paliativos. Rio de Janeiro: Garamond, Editora Fiocruz.

Moritz, R. D., et al. (2009). 1 o Fórum do Grupo de Estudos do Fim da Vida do Cone Sul: Proposta para atendimento do paciente portador de doença terminal internado em UTI. Revista Brasileira de Terapia Intensiva, 21(3), 306-309. doi:10.1590/S0103-507X2009000300011.

Pazin-Filho, A. P. (2005) Morte: Considerações para a prática médica. Medicina, 38(1), 20-25.

Sadala, M. L. A., \& Silva, M. P. (2008). Cuidar de pacientes em fase terminal: A experiência de alunos de medicina. Interface: Comunicação, saúde, educação, 12(24), 7-21. doi:10.1590/S1414-32832008000100002.
Shimizu, H., \& Guitierrez, B. (1997). Participação de enfermeiros na implantação e desenvolvimento de um grupo multidisciplinar de assistência a pacientes crônicos e terminais. Revista Escola Enfermagem USP, 31(2), 251-258. doi:10.1590/ S0080-62341997000200007.

Siqueira-Batista, R., \& Schramm, F. R. (2008). A eutanásia e os paradoxos da autonomia. Ciência \& Saúde Coletiva, 13(1), 95-102. doi:10.1590/ S1413-81232008000100025.

Sousa, A. (1997). 0 atendimento ao paciente terminal. Psicologia Argumento, 15(20), 54-60.

Tonetto, A. M., \& Gomes, W. B. (2007). A prática do psicólogo hospitalar em equipe multidisciplinar. Estudos de Psicologia, 24(1), 89-98. doi:10.1590/ S0103-166X2007000100010.

Torreão, L. (2003). Uso de opióides em pacientes terminais: Sedação ou entanásia? À beira do leito. Revista da Associação Médica Brasileira, 49(2), 117-136. doi:10.1590/S0104-42302003000200011.

Vianna, A., \& Piccelli, V. (1998). O estudante, o médico e o professor de medicina perante a morte e o pacienteterminal. Revista da Associação Médica Brasileira, 44(1), 21-7. doi:10.1590/S0104-42301998000100005. 